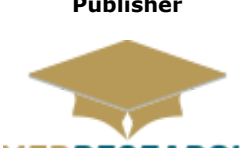

MEDRESEARCH

www.medresearch.in

\section{International Journal of Medical Research and Review}

2020 Volume 9 Number 2 March-April

\title{
Access recirculation and adequacy of hemodialysis in different types of vascular access
}

\author{
Shrijjaa P. ${ }^{1 *}$, V. N. Unni ${ }^{2}$, Prabhakar M. ${ }^{3}$ \\ DOI: https://doi.org/10.17511/ijmrr.2021.i02.11 \\ 1* P. Shrijjaa, MD (General Medicine), MBBS, DM (Nephrology), Consultant Nephrologist, Kalyani Kidney care Centre, Erode, Tamil Nadu \\ 638011, India. \\ 2 V. Narayanan Unni, MBBS, MD (General Medicine), DM (Nephrology), Head of Nephrology Department, Astermedcity, Kochi, Kerala, India. \\ 3 Prabhakar M., MS, DNB (Urology), Consultant Urologist \& Transplant Surgeon, Kalyani Kidney care Centre, Erode, Tamil Nadu 638011, \\ India.
}

Introduction: Haemodialysis requires recirculation, and it happens when dialysed blood returning through the venous needle re-enters the extracorporeal circuit through the arterial needle, rather than returning to the systemic circulation. Significant recirculation should be expected, when there is an inadequate reduction in the values of urea. During End-Stage Renal Disease (ESRD), adequate dialysis is of utmost importance because it influences the morbidity and mortality of the patients. Methods and materials: The study was carried out in 200 patients who underwent haemodialysis at the dialysis unit in Kalyani kidney care centre, Erode. Patients were actively evaluated from February 2018 till November 2018. Patients were randomized and accordingly 64 patients were enrolled in category I Arteriovenous fistula (AVF), 63 Patients in category II Internal Jugular Catheter (IJC) and category III Femoral Catheter (FC) each and 10 patients in category IV Perm Catheter (PC). Success recirculation was estimated and adequacy of haemodialysis was done virtually. Calculated $\mathrm{Kt} / \mathrm{V}$ was done in almost all patients. Results: The mean access recirculation rate was $6.3 \pm 5.1 \%$ in those with AVF, while in IJC and FC groups were $6.7 \pm 4.5 \%$ and $24.4 \pm 11.7 \%$ respectively. When the two groups were compared, AVF vs FC groups, the difference was statistically significant ( $p$ value $<0.001$ ) and in IJC vs FC groups, the difference was statistically less significant ( $p$-value <0.001) in both AR\% and online Kt/V. Conclusion: An arteriovenous2QQ2 fistula has less access recirculation, when compared to temporary catheters. On the other hand, the femoral catheter has more access recirculation, when compared to the internal jugular catheter. The difference in calculated $\mathrm{Kt} / \mathrm{V}$ with the three types of vascular access has no statistical significance.

Keywords: End-Stage Renal Disease (ESRD), Haemodialysis, Recirculation

Corresponding Author

P. Shrijjaa, MD (General Medicine), MBBS, DM (Nephrology), Consultant Nephrologist, Kalyani Kidney care Centre, Erode, Tamil Nadu 638011, India.

Email: shrijjaapann@gmail.com
How to Cite this Article

Shrijjaa P, Unni VN, Prabhakar M. Access recirculation and adequacy of hemodialysis in different types of vascular access. Int J Med Res Rev. 2020;9(2):115-121.

Available From

https://ijmrr.medresearch.in/index.php/ijmrr/article/ view/1272
To Browse

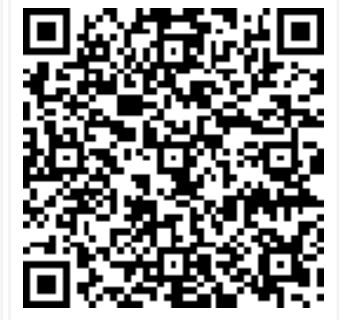

Manuscript Received 2021-03-24

Conflict of Interest No
Review Round 1 2021-04-04

Funding

$\mathrm{Nil}$
Review Round 2 2021-27

Ethical Approval Yes
Review Round 3

Plagiarism X-checker $7 \%$
Accepted 2021-04-30

Note

(C) 2020 by P. Shrijjaa, V. N. Narayanan Unni, M. and Published by Siddharth Health Research and Social Welfare Society. This is an Open Access article licensed under a Creative Commons Attribution 4.0 International License https://creativecommons.org/licenses/by/4.0/ unported [CC BY 4.0]. 


\section{Introduction}

Haemodialysis requires recirculation occurs when dialysed blood returning to the venous needle, reenters the extracorporeal circuit through the arterial needle, rather than returning to the systemic circulation. Significant recirculation can be suspected, when there is an inadequate reduction in the urea values. In ESRD, adequacy of dialysis is important because it influences the morbidity and mortality of the patients. Recirculation is one of the factors responsible for inadequacy of Haemodialysis, for assessing the access recirculation; methods available are urea dilution method and non-urea dilution methods (Glucose Infusion Method, Saline Infusion Method, Ultrasound Dilution Method, and Conductivity Method) [1].

The most common causes of access recirculation are inadequate arterial blood flow rate, the presence of high-grade venous stenosis, and improper needle placement by hemodialysis staff during hemodialysis $[2,3,4]$.

High-grade venous stenosis can restrict dialyzed blood venous outflow, thereby, sometimes leading to backflow of some dialyzed blood to the dialytic circuit through the arterial needle. Therefore, in this situation blood entering the dialyzer through the arterial side will become diluted with blood that has just left the dialyzer and as a result, the effective clearance obtained in the course of a hemodialysis session is reduced. Access recirculation can also be induced by inadequate arterial inflow when the A-V fistula blood flow rate is less than the blood pump of the hemodialysis machine. [4]. In this setting, the backflow of some dialyzed blood from the venous side of the access to the arterial side is necessary to support the extracorporeal blood flow rate set by the blood pump.

The measurement of dialysis access recirculation among ESRD patients undergoing maintenance hemodialysis has important diagnostic implications. The presence of access recirculation should be suspected when there is an inadequate reduction in the blood urea concentration, as shown by the postdialysis blood urea concentration exceeding 40 percent of the pre-dialysis blood urea concentration. Therefore, high degrees of access recirculation in long term can lead to significant inadequate dialysis. It is well established that inadequate dialysis is an important contributor to lower overall survival among these patients.
It is also suggested that the presence of access recirculation is one of the surrogate markers of $A-V$ fistula inflow problems among hemodialysis patient and early detection and treatment of these problems improves long-term access patency rates. Therefore, periodic assessment of access recirculation may have an important effect on the management of ESRD patients undergoing maintenance hemodialysis.[5].

The present study aims to assess the vascular access recirculation in different types of vascular accesses used for hemodialysis. This study also compares online $\mathrm{Kt} / \mathrm{V}$ and calculated $\mathrm{Kt} / \mathrm{V}$, and the evaluation of selected cases of AV fistula dysfunction with doppler/fistulogram.

\section{Materials and Methods}

An open-label, prospective study was carried out on 200 patients who underwent haemodialysis at the dialysis unit in Kalyani kidney care centre, Erode. The study duration was between November 2017 to December 2018 and patients were recruited and randomized from February 2018 till November 2018. The study group included AKI (Acute Kidney Injury) and ESRD (End-Stage Renal Disease). The patients underwent haemodialysis through AVF (Arteriovenous fistula) - Category I, IJC (Internal jugular catheter) Category II, FC (Femoral catheter) Category III and PC (Perm catheter) Category IV. There were 64 patients in Category I, 63 Patients in Category II and III each and 10 patients in Category IV. AR (Access Reticulation) percentage and adequacy of haemodialysis are done online and calculated $\mathrm{Kt} / \mathrm{V}$ was done in all patients. Fistulogram was done for few patients in Category I.

For clinical assessment, vascular access recirculation, the technique used was year-based measurement (Two needles with three samples of blood). Recirculation percentage was calculated as(S-A)/(S-V) $\times 100$ where $S$ is a systemic blood sample; $A$ is an arterial blood sample and $V$ is a venous blood sample. Assess recirculation $>10 \%$ was taken as significant [NKF-K/DOQI Guidelines].

For the clinical study, adequacy of haemodialysis, $\mathrm{Kt} / \mathrm{V}$ was calculated with dialyzer urea clearance $(K)$, time duration of dialysis(t) and volume of distribution of urea $(\mathrm{V})$. $\mathrm{K}$ was estimated from (Cbi$\mathrm{Cbo}) /(\mathrm{Cbi}-\mathrm{xQb})$ where Cbi-Blood concentration of salute (urea) at dialyzer inlet, Cbo Blood concentration of solute(urea) at dialyzer outlet, QbBlood flow rate. 
Urea distribution volume $(\mathrm{V})$ was determined from the Watson equations for men and women. Kt/V was also measured with online clearance monitoring (OCM) in Fresenius machine 4000S.Kt/ $\mathrm{V}$ less than 1.2 was taken as an indicator of inadequate dialysis.

Based on the results observed in the existing literature on the comparison of vascular access recirculation percentage in the temporary catheter, permanent catheter and AVF [6].

And with $95 \%$ confidence and $90 \%$ power, the sample size arrives at 63 in each group. In this study, there were 63 patients each in femoral catheter and internal jugular catheter groups and 64 in AVF group.

The data obtained were compiled and statistically analyzed. ANOVA test was used in this study to compare the means of online $\mathrm{Kt} / \mathrm{V}$ and calculated $\mathrm{Kt} / \mathrm{V}$, and the evaluation of selected cases of $\mathrm{AV}$ fistula dysfunction with doppler/fistulogram.

This study was approved by the Institutional Ethics and Research Committee, Kalyani Kidney care Centre, Erode.

\section{Results}

Table 1: Type of vascular access, $A R \%$ and online and calculated $\mathrm{KT} / \mathrm{V}$

\begin{tabular}{|l|l|l|l|}
\hline $\begin{array}{c}\text { Types of vascular } \\
\text { access }\end{array}$ & $\begin{array}{c}\text { No. of } \\
\text { patients }\end{array}$ & \multicolumn{1}{|c|}{$\begin{array}{c}\text { Vascular access } \\
\text { recirculation }(>10 \%)\end{array}$} & $\begin{array}{c}\text { Calculated } \\
\mathbf{K t} / \mathbf{V}\end{array}$ \\
\hline Cat I AVF & 64 & 15 & 13 \\
\hline Cat II IJC & 63 & 12 & 20 \\
\hline Cat III FC & 63 & 51 & 20 \\
\hline Cat IV PC & 10 & 0 & 2 \\
\hline
\end{tabular}

The study was conducted on 200 patients. There were 64 patients with arteriovenous fistula (AVF), 63 patients with the internal jugular catheter (UC) and femoral catheter (FC), and 10 patients with perm catheter. Vascular access recirculation technique was performed in 15 patients in category I, 15 and 12 patients in category II and III respectively. Calculated $\mathrm{Kt} / \mathrm{V}$ in 13 patients in the AVF group, 20 patients each in IJC and FC group, and 2 patients in category IV.

Table-2: No of patients and \% of access recirculation

\begin{tabular}{|l|l|l|l|l|}
\hline \multicolumn{1}{|c|}{ Access } & \multicolumn{1}{c|}{ AVF } & \multicolumn{1}{c|}{ IJC } & \multicolumn{1}{c|}{ FC } & \multicolumn{1}{c|}{ PC } \\
\hline$<5$ & 33 & 27 & 3 & 8 \\
\hline $5-10$ & 16 & 24 & 8 & 2 \\
\hline $10-15$ & 10 & 9 & 3 & - \\
\hline
\end{tabular}

\begin{tabular}{|l|l|l|l|l|}
\hline $15-20$ & 4 & 3 & 5 & - \\
\hline$>20$ & 1 & 0 & 44 & - \\
\hline Total & 64 & 63 & 63 & 10 \\
\hline
\end{tabular}

Access recirculation (AR\%) in AVF is calculated for 64 patients with less than $5 \%$ in 33 patients and more than $20 \%$ in 1 patient. (AR\%) in IJC is calculated for 63 patients with $<5 \%$ in 27 patients. . $(A R \%)$ in $F C$ is calculated for 63 patients with $<5 \%$ access in 3 patients and $>20 \%$ in 44 patients. $(A R \%)$ in $P C$ is calculated for 10 patients with $<5 \%$ access in 8 patients.

Table 3: Mean and Standard deviation

\begin{tabular}{|l|l|l|l|l|}
\hline & \multicolumn{1}{|c|}{$\begin{array}{c}\text { AVF } \\
(\text { Mean+SD })\end{array}$} & \multicolumn{1}{|c|}{$\begin{array}{c}\text { IJC } \\
\text { (Mean+SD })\end{array}$} & $\begin{array}{c}\text { FC } \\
\text { (Mean+SD })\end{array}$ & $\begin{array}{c}\text { PC } \\
\text { (Mean+SD) }\end{array}$ \\
\hline AR & $6.3 \pm 5.1$ & $6.7 \pm 4.3$ & $24.4 \pm 11.7$ & $2.8 \pm 1.7$ \\
\hline Online & $1.0 \pm 0.18$ & $0.9 \pm 0.15$ & $0.8 \pm 0.2$ & $1.0 \pm 0.2$ \\
\hline Calculated & $1.35 \pm 0.2$ & $1.28 \pm 0.22$ & $1.3 \pm 0.3$ & $1.5 \pm 0.2$ \\
\hline
\end{tabular}

The mean recirculation rate was $6.3 \pm 5.1 \%$ for AVF group, was $6.7 \pm 4.3 \%$ for IJC group, was $24.4 \pm 11.7 \%$ for the FC group and was $2.8 \pm 1.7 \%$ for the PC group. The mean online $\mathrm{Kt} / \mathrm{V}$ was $1.0 \pm 0.18 \%$ for the AVF group, was $0.9 \pm 0.15 \%$ for the IJC group, was $0.8 \pm 0.2 \%$ for the FC group and was $1.0 \pm 0.2 \%$ for the $P C$ group. The mean calculated $\mathrm{Kt} / \mathrm{V}$ was $1.35 \pm 0.2 \%$ for the AVF group, was $1.28 \pm 0.22 \%$ for the IJC group, was $1.3 \pm 0.3 \%$ for the FC group and was $1.5 \pm 0.2 \%$ for the PC group.

Table 4: Statistical significance of three types of accesses with $A R$, Online $K t / V$ and calculated $\mathrm{Kt} / \mathrm{V}$

\begin{tabular}{|l|l|l|l|l|}
\hline & $\begin{array}{c}\text { AFV }(n=64) \\
(\text { Mean+SD })\end{array}$ & $\begin{array}{c}\text { IJC }(n=63) \\
(\text { Mean+SD })\end{array}$ & \multicolumn{1}{|c|}{$\begin{array}{c}\text { FC }(n=63) \\
(\text { Mean+SD })\end{array}$} & $\begin{array}{c}\text { p } \\
\text { value }\end{array}$ \\
\hline AR & $6.3 \pm 5.1$ & $6.7 \pm 4.3$ & $24.4 \pm 11.7$ & $\begin{array}{l}<0.00 \\
1\end{array}$ \\
\hline Online & $1.0 \pm 0.18$ & $0.9 \pm 0.15$ & $0.8 \pm 0.2$ & $\begin{array}{l}<0.00 \\
1\end{array}$ \\
\hline Calculated & $1.35 \pm 0.2$ & $1.28 \pm 0.22$ & $1.3 \pm 0.3$ & 0.15 \\
\hline
\end{tabular}

$P$ value for three types of accesses with $A R$ and Online Kt/V was found to be $<0.001$. The P-value for three types of accesses with calculated Kt/ $\mathrm{V}$ was found to be 0.15 .

Table 5: Comparison of $\mathrm{AR} \%$ and online $\mathrm{Kt} / \mathrm{V}$ in different types of vascular access

\begin{tabular}{|l|l|l|}
\hline \multicolumn{1}{|c|}{ Types of vascular access } & AR\% p-value & \multicolumn{1}{|c|}{ Online $p$-value } \\
\hline AVF vs IJC & 1.0 & 0.18 \\
\hline AVF vs FC & $<0.001$ & $<0.001$ \\
\hline IJC vs FC & $<0.001$ & $<0.001$ \\
\hline
\end{tabular}


When comparing the statistical significance of AR\% in different types of vascular access, in AVF vS IJC groups, the difference is statistically not significant p-value-1.0), in AVF vs. FC groups, the difference is statistically significant ( $p$-value $<0.0001$. Comparing the statistical significance of online $\mathrm{Kt} / \mathrm{V}$ in different types of vascular access. In AVF vs IJC groups, the difference is statistically not significant ( $p$ value<0.001) and in IJC vs FC groups also statistically significant ( $p$ value $<0.001$ ).

Table 6: Correlation of vascular access recirculation with age in the three types of access

\begin{tabular}{|l|l|l|}
\hline & \multicolumn{1}{|c|}{ Age (mean+sd) } & \multicolumn{1}{c|}{ p value } \\
\hline AVF & $56.3 \pm 14.6$ & 0.78 \\
\hline IJC & $52.3 \pm 14.1$ & 0.52 \\
\hline JC & $55.3 \pm 18.0$ & 0.13 \\
\hline
\end{tabular}

The mean age of the patients in AVF, IJC and FC groups was $56.3 \pm 14.6$ years, $52.3 \pm 14.1$ years and $55.3 \pm 18$ years respectively. When vascular access recirculation in AVF, IJC and FC was correlated with age, the p-value was $0.78,0.52$ and 0.13 respectively.

Table 7: Correlation of gender with vascular access recirculation in the three types of access

\begin{tabular}{|c|c|c|c|}
\hline & & Age $($ mean+sd) & $\mathrm{p}$ value \\
\hline \multirow[t]{2}{*}{ AVF } & M & $6.06 \pm 4.9$ & \multirow[t]{2}{*}{0.324} \\
\hline & $\mathrm{F}$ & $7.7 \pm 5.8$ & \\
\hline \multirow[t]{2}{*}{ IJC } & M & $6.2 \pm 4.3$ & \multirow[t]{2}{*}{0.184} \\
\hline & $\mathrm{F}$ & $7.9 \pm 4.8$ & \\
\hline \multirow[t]{2}{*}{ JC } & M & $23.8 \pm 11.9$ & \multirow[t]{2}{*}{0.401} \\
\hline & $\mathrm{F}$ & $26.6 \pm 11.2$ & \\
\hline
\end{tabular}

When vascular access recirculation in AVF, IJC and FC was correlated with gender, the p-value was $0.324,0.184$ and 0.401 respectively.

\section{Discussion}

In Haemodialysis patients, for assessing the access recirculation, methods available are urea dilution method and non-urea dilution methods (Glucose Infusion Method, Saline Infusion Method, Ultrasound Dilution Method and Conductivity Method). A modified CRIT-line monitor is used to measure access recirculation and found to be in good correlation with urea measurements. Soon, at least four competing technologies will be available to measure access flow and recirculation: Ultrasound dilution (Transonics), optical Haematocrit (In-line
Diagnostics/B Braun), Haemodilution (Fresenius) and Conductivity (Cobe/Hospital).

Haemodialysis (HD) access recirculation occurs when dialysed blood returning through the venous needle re-enters the extracorporeal circuit through the arterial needle rather than returning to the systemic circulation. As a result, the efficacy of dialysis is reduced and high degrees of recirculation can lead to a significant discrepancy between the amounts of HD delivered. High degrees of access recirculation indicate the presence of access stenosis, the most common cause of access thrombosis. Access recirculation is usually due to high-grade stenosis which obstructs venous outflow, leading to backflow into the arterial needle. There are two other common causes. Firstly, access recirculation can be induced by inadequate arterial inflow; in this setting backflow from the venous limb of the access is necessary to support the extracorporeal blood flow rate set by the pump. Secondly, access recirculation can result from improper needle placement. The proximity of the needles will increase the re-entry of dialysed blood into the arterial needle. In some centres, misplacement of needles is a common source of recirculation, even after such placement had been previously recognised.[7].

In our study, we used urea-based measurement (Two needles with three samples of blood) for measuring AR\%. There are seven steps to collect the samples. Tests are performed after approximately 30minutes of haemodialysis treatment and after turning off ultra-filtration. These are as follows:

01. Draw arterial (A) and venous (V) line samples from the extracorporeal circuit ( $A$ is an arterial blood sample and $\mathrm{V}$ is a venous blood sample).

02. Reduce blood flow rate (BFR) to $120 \mathrm{ml} / \mathrm{min}$.

03. Turn off the blood pump exactly 10 seconds after reducing BFR.

04. Clamp arterial line immediately above sampling port.

05. Draw systemic arterial sample (S) from arterial line port.

06. Unclamp line and resume dialysis.

07. Measure BUN in $A, V$, and $S$ samples and calculate percent recirculation. Access recirculation (AR \%) was calculated with the formula $((S-A) /(S-V)) \times 100$. 
The study was conducted on 200 patients. There were 64 patients with arteriovenous fistula (AVF), 63 patients with the internal jugular catheter (UC) and femoral catheter (FC), and 10 patients with perm catheter. As we have only 10 patients with perm catheter were excluded from statistical analysis. The statistical analysis was done for 190 patients.

Access recirculation (AR\%) in AVF is calculated for 64 patients. The mean recirculation rate was $6.3 \pm 5.1 \%$. Besarab et al [8]. found an average recirculation value of $5.5 \pm 0.8 \%$ in their patients. Javadsalimi et al [7]. found the mean recirculation rate was $8.7 \%$ and Bay et al [9]. has reported a recirculation rate of $11.8 \pm 9.9 \%$ in their patients.

$11(17.1 \%)$ patients with AVF in this study had AR $>10 \%$. Out of 11 patients,7 (63.6\%) patients expired due to various problems. The age of these patients was in between 65 to 80 years for 6 patients, except for one patient who was 50 years old.

Dialysis dose quantification utilizing $\mathrm{Kt} / \mathrm{V}$ is of fundamental importance in prescribing and in assessing the adequacy of the dialysis delivered which is related to patient morbidity and mortality [10]. Three main factors affect the urea clearance in the blood water portion: blood flow speed, the dialysis solution flow speed and the number of uses of the dialyzer.

Adequacy of $\mathrm{HD}$ can be calculated with URR and $\mathrm{Kt} / \mathrm{V}$ methods. In our study $\mathrm{Kt} / \mathrm{V}$ was used. $\mathrm{K}$ was estimated from (Cbi-Cbo)/ CbixQb. (Cbi: Blood concentration of solute at dialyzer inlet, Cbo: Blood concentration of solute at dialyzer outlet $\mathrm{Qb}$ : Blood flow rate). The Urea distribution volume $(V)$ is determined from the Watson equations for men and women. [11]. Kt/V was also measured with online clearance monitoring (OCM).

[Male $\quad$ TBW $=2.447-(0.09156$ Xage $)$

(0.1074xheight) $+(0.3362 \times$ weight $)$ Female $\quad$ TBW $=-2.097+\quad(0.1069 \times$ height $) \quad+$
$(0.2466 \times$ weight $)]$

Advances in the online monitoring of conductivity during $H D$ sessions have made the repeated measurement of $\mathrm{Kt} / \mathrm{V}$ on all HD treatment sessions a practical proposition. Multiple measurements are necessary to produce an average delivery dose and take a decision on dialysis prescription. In AVF patients, Calculated $\mathrm{Kt} / \mathrm{V}<1.2$ was seen in
$13(20.3 \%)$ patients, while online $\mathrm{Kt} / \mathrm{V}<1.2$ was seen in $48(75 \%)$ of 64 patients.

The mean of online $\mathrm{Kt} / \mathrm{V}$ was $1.04 \pm 0.18$, mean of calculated $\mathrm{Kt} / \mathrm{V}$ was 1.3 \pm 0.28. AI Saran et al from a centre in Saudi Arabia did a study like ours in chronic HD patients and found mean calculated Kt/V was $1.37 \pm 0.09$ and mean online $\mathrm{Kt} / \mathrm{V}$ was $1.02 \pm 0.15[10]$. In patients with AVF, calculated $\mathrm{Kt} / \mathrm{V}>1.2$ was seen in $51(79.7 \%)$ patients, while online $\mathrm{Kt} / \mathrm{V}>1.2$ was seen in $15(25 \%)$ of 64 patients.

A total of 200 patients on HD were studied and a male preponderance of 145 . The mean age of the patients in AVF, IJC and FC groups was 56.3 \pm 14.6 years, $52.3 \pm 14.1$ years and $55.3 \pm 18$ years respectively. When vascular access recirculation in AVF, IJC and FC was correlated with age, the $\mathrm{p}$ value was $0.78,0.52$ and 0.18 respectively. Thus, age did not correlate with AR in any of the vascular access groups. Salimi J et al also showed no significant correlation between AR and age, gender, history of hypertension, diabetes mellitus, access age and duration on dialysis therapy. [7].

Gender does not influence AR-p value is 0.095 also age does not influence AR-p value is 0 . 091. The length of the catheter (both FC and IJC) was 13. $5 \mathrm{~cm}$. Each group had 63 patients. In the group with IJC, calculated Kt/V<1.2 was seen in $20(31.7)$ patients, whereas online $\mathrm{Kt} / \mathrm{V}<1.2$ was $56(88.8 \%)$ of 63 patients. In the group with FC, calculated $\mathrm{Kt} / \mathrm{V}<1.2$ was seen in $20(31.7 \%)$ patients, whereas online $\mathrm{Kt} / \mathrm{V}<1.2$ was $60(95.2 \%)$ of 63 patients.

The mean recirculation rate in IJC and FC groups was 6.7 and $24.4 \%$ respectively. In 12 patients (19\%) with IJC and 51 patients with FC (80.9\%) has $A R>10 \%$. Comparing $A R \%$ in IJC and FC patients, there was statistical significance $(p<0.001) . A R \%$ Was more in FC patients. Like our study, Little MA et al [12] showed higher recirculation in FC than in IJC; FC shorter than 20 $\mathrm{cm}$ had a significant access recirculation rate of $26.3 \%$, whereas longer than $20 \mathrm{~cm}$ had $8.3 \%$ $(p=0.007)$. These results were again confirmed by Leblance et al, $[6,10]$. who showed a $22 \%$ rate of recirculation in shorter $\mathrm{FC}(13.5 \mathrm{~cm})$.

In the groups with IJC, calculated KT/V>1.2 was seen in $43(68.2 \%)$ patients, whereas online $\mathrm{Kt} / \mathrm{V}>1.2$ was $7(11.1 \%)$ of 63 patients. In the group with FC, calculated $\mathrm{Kt} / \mathrm{V}>1.2$ was seen in $43(68.2 \%)$, whereas online $\mathrm{Kt} / \mathrm{V}>1.2$ was $3(4.8 \%)$ of 63 patients. 
The important factor which determines the AR is probably the flow rate in the vein in which the catheter tip lies. If the flow of venous blood through this region is less than the blood flow rate set on the dialysis machine, then the extra blood is drawn from freshly dialysed blood exiting the venous tip of the catheter. Under normal circumstances, the flow through the internal jugular vein and inferior vena cava approach 2L/min; thus, recirculation should only occur if there is reduction or reversal of flow, may happen during positive-pressure ventilation or in the presence of atrioventricular dissociation. Conversely, the femoral vein only receives blood from one leg, and when dialysed blood flow exceeds that in the femoral/iliac vein, blood will recirculate to meet this demand. FC longer than $20 \mathrm{~cm}$ frequently reaches the common iliac vein and may even reach the inferior vena cava, where there is more blood flow.

In normal circumstances, regional blood flow rates to the lower extremities may be less than those found in the superior vena cava. These differences in venous blood flow rates probably are responsible for greater recirculation in patients with $15 \mathrm{~cm}$ femoral catheters compared with patients with internal jugular, subclavian and $24 \mathrm{~cm}$ femoral catheters. In addition to that, hemodynamic changes during HD might cause further reduction in blood flow rate. [8].

The mean access recirculation rate in IJC and FC groups were $6.7 \pm 4.5 \%$ and $24.4 \pm \quad 11.7 \%$ respectively. In IJC and FC groups, the mean calculated $\mathrm{Kt} / \mathrm{V}$ were $1.28 \pm 0.22$ and $1.31 \pm 0.27$ respectively. The mean online $\mathrm{Kt} / \mathrm{V}$ was $0.98 \pm 0.15$ and $0.82 \pm 0.21$ respectively.

We tried to compare the statistical significance of $A R \%$ in different types of vascular access. In AVF vs IJC groups, the difference is statistically not significant $p$-value-1.0), in AVF vs. FC groups, the difference is statistically significant ( $p$-value $<0.0001$ ).

Comparing the statistical significance of online Kt/ $\mathrm{V}$ in different types of vascular access. In AVF vs IJC groups, the difference is statistically not significant ( $\mathrm{p}$ value $<0.001$ ) and in IJC Vs FC groups also statistically significant ( $p$ value $<0.001$ )

When we analysed the statistical significance of the calculated Kt/V with the Anova test, we found that it is not statistically significant ( $p$-value 0.15 ). Hence calculated Kt/V was not compared with different types of vascular access.
Similarly, like our study, Saran et al showed that $\mathrm{Kt} / \mathrm{V}$ obtained using online conductivity monitoring indicated a lower intermittent HD adequacy than those calculated from urea measurements. [10]. He stated that there is a moderate correlation between calculated and online Kt/V. Kelly Cristina Inouse et al concluded there is no relation between the calculated $\mathrm{Kt} / \mathrm{V}$ and the machine $\mathrm{Kt} / \mathrm{V}$. [1]. Chand $\mathrm{DH}$ et al feels that dialysis using central venous access is associated with a decreased dose of haemodialysis. [8].

In this study, we have taken 10 patients with perm cath. As the number is less, this is not included in the statistical analysis. In this group, AR\% was $0 \%$, calculated $\mathrm{Kt} / \mathrm{V}<1.2$ was seen in 2 patients out of 10 and online Kt/V >1.2 was seen in 8 out of 10 patients.

Of the 64 patients studied with AVF, the patients who had $A R>10 \%$ and blood flow of $<250 \mathrm{ml} / \mathrm{min}$ were taken for further evaluation of AV fistula with Doppler/Fistulogram. Colour sonography was done for 7 patients. Of these, 4 patients had fistula dysfunction (i.e. stenosis) and the other 3 had normal blood flow through the fistula in CDUS.

Fistulogram was done for 3 patients; other 4 patients were too lost follow up as they changed their centre for haemodialysis, out of these 3 who underwent fistulogram, 2 patients had stenosis in cephalic vein; the other had normal blood flow.

\section{Conclusion}

AVF has less access recirculation when compared to temporary catheters. A femoral catheter has more access recirculation, when compared to the internal jugular catheter. The difference is calculated Kt/V with the three types of vascular access has no statistical significance.

\section{What does this study add to present knowledge?}

A femoral catheter has more access recirculation, when compared to the internal jugular catheter.

\section{Author contribution}

PS: conceptual framework, data collection.

VNNU: a review of literature, methodology review.

PS, MP: manuscript writing and editing. 


\section{Reference}

01. Shayanpour S, Faramarzi M. Arteriovenous Fistula Recirculation in Hemodialysis. Nephrourol Mon. 2015 Jul 22;7(4)e27474.

doi: $10.5812 /$ numonthly.27474 [Crossref]

02. Mousavi SB, Tavazoe M, Hayati F, Sametzadeh M. Arterio-Venous fistula recirculation in hemodialysis- causes and prevalences. Shiraz E Med J. 2010;11(4)219-24.

Doi: [Article] [Crossref]

03. Sherman RA, Matera JJ, Novik L, Cody RP. Recirculation reassessed- the impact of blood flow rate and the low-flow method reevaluated. Am J Kidney Dis. 1994 Jun;23(6)846-8. doi: $10.1016 / s 0272-6386(12) 80138-7$ [Crossref]

04. Schneditz D. Recirculation, a seemingly simple concept. Nephrol Dial Transplant. 1998 Sep; 13(9)2191-3.

doi: $10.1093 /$ ndt/13.9.2191 [Crossref]

05. Zeraati A, Beladi Mousavi SS, Beladi Mousavi M. A review article- access recirculation among end stage renal disease patients undergoing maintenance hemodialysis. Nephrourol Mon. 2013;5(2)728-32.

doi: $10.5812 /$ numonthly. 6689 [Crossref]

06. Inoue KC, Kuroda CN, Nakayama KG, Dell'Agnolo CM, Matsuda LM. Comparison between two methods for evaluation of the dialysis dose quality. Acta Paul Enferm. 2009;22(special issue 1)494-6.

DOI: $10.1590 / S 0103-21002009000800007$ [Crossref]

07. Salimi J, Razeghi E, Karjalian H, Meysamie A, Dahhaz M, Dadmehr $M$. Predicting hemodialysis access failure with the measurement of dialysis access recirculation. Saudi J Kidney Dis Transpl. 2008 Sep;19(5)781-4.

[Crossref]

08. Besarab A, Sherman R. The relationship of recirculation to access blood flow. Am J Kidney Dis. 1997 Feb;29(2)223-9.

doi: $10.1016 / s 0272-6386(97) 90033-0$ [Crossref]
09. Bay WH, Henry ML, Lazarus JM, Lew NL, Ling J, Lowrie EG. Predicting hemodialysis access failure with color flow Doppler ultrasound. Am J Nephrol. 1998;18(4)296-304.

doi: $10.1159 / 000013354$ [Crossref]

10. Al Saran K, Sabry A, Abdulghafour M, Yehia A. Online conductivity monitoring of dialysis adequacy versus $\mathrm{Kt} / \mathrm{V}$ derived from urea reduction ratio- a prospective study from a Saudi Center. Ren Fail. 2010 Jan;32(1)36-40. doi: $10.3109 / 08860220903367486 \quad$ [Crossref]

11. Watson PE, Watson ID, Batt RD. Total body water volumes for adult males and females estimated from simple anthropometric measurements. Am J Clin Nutr. 1980 Jan;33(1)27-39.

doi: $10.1093 / a j c n / 33.1 .27$ [Crossref]

12. Little MA, Conlon PJ, Walshe JJ. Access recirculation in temporary hemodialysis catheters as measured by the saline dilution technique. Am J Kidney Dis. 2000 Dec;36(6)1135-9. doi: 10.1053/ajkd.2000.19821 [Crossref] 